\title{
Mandibular changes associated with maxillary impaction and molar intrusion
}

\author{
Sondos Abuzinada, Fahad Alsulaimani
}

King Abdulaziz University, Jeddah, Saudi Arabia

Email: sondoz@hotmail.com

Received 29 October 2013; revised 29 November 2013; accepted 11 December 2013

Copyright (C) 2013 Sondos Abuzinada, Fahad Alsulaimani. This is an open access article distributed under the Creative Commons Attribution License, which permits unrestricted use, distribution, and reproduction in any medium, provided the original work is properly cited.

\begin{abstract}
We report a case series of ten patients who presented with anterior open bite. The initial evaluation included clinical pictures, lateral cephalometric radiographs and dental casts. They were assessed according to the severity of the open bite and the cause (skeletal or dental). They all underwent orthodontic treatment as an initial step. Five patients with dental open bite underwent molar intrusion using titanium screws and five patients underwent maxillary Le Fort I impaction. We report the mandibular changes associated with these different treatment modalities with improved esthetics.
\end{abstract}

Keywords: Maxillary Impaction; Molar Intrusion; Open Bite; Le Fort I; Titanium Screws

\section{INTRODUCTION}

Vertical Maxillary Excess (VME) is one of the most frequently encountered dentofacial deformities. This can result in an anterior open bite or an unesthetic gummy smile. The correction of vertical problems with or without open bite usually includes maxillary Le Fort I impaction [1]. On the other hand, the correction of an open bite can be managed orthodontically by molar intrusion [2].

The mandible in such cases is either retrognathic or within normal position and will respond to the superior positioning of the maxilla by autorotation. In some cases this autorotation will add the need to perform mandibular surgery to either advance or setback the mandible and is case-dependent $[3,4]$. With the mandibular autorotation, the chin position advances. This can be estimated in the presurgical prediction, but requires great accuracy as this will decide if only maxillary Le Fort I impaction will need or two jaw surgeries. Some studies have been made for predicting mandibular autorotation following manxillary impaction $[5,6]$. However, controversies in locating the center of mandibular autorotation revealed the inability to accurately predict the final position of the mandible after maxillary impaction [6-8]. On the other hand, it has been documented that the mandible will move forward following maxillary impaction with a chin advancement in $1: 1$ ratio [9].

Molar intrusion is used to manage an open bite. A number of patients do not wish to perform orthognathic surgery because of the involved risk. For such patients, various alternatives can be used, including multibrackets in conjunction with high-pull headgear therapy (2), multiple-loop edgewise arch wire (MEAW) therapy (3), reversed curve nickel-titanium wire with intermaxillary elastics (4) and extraction therapy (5). These treatment modalities can achieve acceptable overbite and interincisal relationship which also guide the mandible and chin into a new position leading to a more esthetic appearance [10].

In this article we present a series of cases. Some underwent orthodontic molar intrusion and others underwent maxillary Le Fort I impaction. We compare the changes in mandibular position and the resulting esthetic improvement for each technique.

\section{PATIENTS AND METHODS}

10 patients presented to our joint maxillofacial surgery and orthodontics clinic. Their age group varied between 15 and 27 years. Their chief complaint included a combination of anterior open bite and "a gummy smile". They all underwent a detailed clinical examination which included, radiographs (lateral cephalograms, orthopantograms OPG), dental models and photographs. Cephalometric analysis was done for all 10 patients using Stiner analysis. The treatment plan was established after correlating cephalometric analysis with clinical presenta- 
tion and the chief complaint. The treatment plan for patients diagnosed with vertical maxillary excess and retrognathia included presurgical orthodontic treatment (leveling, alignment and decompensation) followed by maxillary Le fort 1 osteotomy with impaction and fixation using four $1.5 \mathrm{~mm}$ miniplates. This was followed by an advancement genioplasty according to patients need. However, patients diagnosed with anterior open bite without vertical maxillary excess underwent orthodontic treatment. The cause of the anterior open bite in these cases was suggested to have been extrusion of both upper molars, based on cephalometric readings, therefore, the plan was to intrude both upper molars using implanted titanium screws to deliver the force.

\section{ORTHODONTIC TREATMENT FOR OPEN BITE}

Bonding and banding of all teeth, using 0.022-inch slot, preadjusted edgewise appliances were placed in both arches (Victory Series ${ }^{\mathrm{TM}}$, Roth Rx, 3M Unitek, Monrovia, CA, USA) and leveling and aligning phase using progressive sequencing of arch wires. was performed. Correction of the two-step occlusal plane was done during the leveling and aligning phase by extrusion of anterior teeth. Once a heavy stainless steel arch wire $\left(0.019 " \times 0.025^{\prime \prime}\right)$ was reached, Titanium screws $(1.6-\mathrm{mm}$ diameter, $8-\mathrm{mm}$ length; (RMO Co. Ltd., Denver, Colorado, USA) were inserted bilaterally in the alveolar bone of the maxilla through the buccal mucosa between the second bicuspid and the first molar from both the labial and palatal area in some patients as needed. All the screws were implanted at the same visit under local anesthesia was administered. Analgesics were prescribed to the patients for 3 days after the implantation. One week after implantation of the titanium screws, intrusion of posterior teeth began using elastic chains. The total active treatment period was 19 months. The implant screw anchorage was stable for the entire duration of the treatment, and the screws were removed during the retention phase. Another cephalometric radiograph was taken upon completion of orthodontic treatment and Stiner analysis was repeated.

\section{RESULTS}

Five patients with anterior open bite and VME underwent orthognathic surgery (Le fort I maxillary impaction with more posterior impaction. An advancement genioplasty was also done in three patients. Five patients with anterior open bite underwent orthodontic treatment only. The results of the cephalometric analysis are listed in (Table 1). The counter clockwise rotation of mandibular plane improved the chin position in three patients who underwent orthodontic treatment (Figure 1) and in all five patients who underwent maxillary impaction this was demonstrated by a decrease in mandibular plane angle and an increase in SNA (Figure 2). Two patients who underwent orthodontic treatment for closure of anterior open bite showed clockwise rotation of the mandibular plane with an increase in mandibular plane angle and a minimal decrease in SNB. However, all patients showed improvement in facial profile and function. The

Table 1. Cephalometric values for patients who underwent molar intrusion and patients who underwent maxillary impaction (DX: diagnosis; DOB: dental anterior open bite).

\begin{tabular}{|c|c|c|c|c|c|c|c|}
\hline Patient number & Dx & Incisal show at rest & Open bite (mm) & Man plane & Occlusal plane & Point $\mathrm{B}$ to $\mathrm{N}^{-}{ }_{\mathrm{FH}}$ & SNB \\
\hline 1 & DOB & $3 \mathrm{~mm}$ & $5 \mathrm{~mm}$ & $\begin{array}{l}30 \\
25\end{array}$ & $\begin{array}{c}14 \\
8\end{array}$ & $\begin{array}{l}0 \\
2\end{array}$ & $\begin{array}{l}70 \\
73\end{array}$ \\
\hline 2 & DOB & $3 \mathrm{~mm}$ & $4 \mathrm{~mm}$ & $\begin{array}{l}47 \\
45\end{array}$ & $\begin{array}{l}16 \\
20\end{array}$ & $\begin{array}{l}10 \\
10\end{array}$ & $\begin{array}{l}75 \\
72\end{array}$ \\
\hline 3 & DOB & 2 & $4 \mathrm{~mm}$ & $\begin{array}{l}38 \\
36\end{array}$ & $\begin{array}{l}17 \\
16\end{array}$ & $\begin{array}{c}9 \\
10\end{array}$ & $\begin{array}{l}85 \\
84\end{array}$ \\
\hline 4 & DOB & 3 & $5 \mathrm{~mm}$ & $\begin{array}{l}35 \\
33\end{array}$ & $\begin{array}{l}15 \\
17\end{array}$ & $\begin{array}{l}6 \\
6\end{array}$ & $\begin{array}{l}82 \\
80\end{array}$ \\
\hline 5 & DOB & $4 \mathrm{~mm}$ & $5 \mathrm{~mm}$ & $\begin{array}{l}39 \\
36\end{array}$ & $\begin{array}{l}18 \\
15\end{array}$ & $\begin{array}{l}6 \\
8\end{array}$ & $\begin{array}{l}81 \\
81\end{array}$ \\
\hline 6 & VME & $5 \mathrm{~mm}$ & $4 \mathrm{~mm}$ & $\begin{array}{l}52 \\
50\end{array}$ & $\begin{array}{l}19 \\
18\end{array}$ & $\begin{array}{c}13 \\
9\end{array}$ & $\begin{array}{l}80 \\
84\end{array}$ \\
\hline 7 & VME & $7 \mathrm{~mm}$ & $4 \mathrm{~mm}$ & $\begin{array}{l}49 \\
44\end{array}$ & $\begin{array}{l}17 \\
14\end{array}$ & $\begin{array}{l}10 \\
10\end{array}$ & $\begin{array}{l}72 \\
73\end{array}$ \\
\hline 8 & VME & $8 \mathrm{~mm}$ & - & $\begin{array}{l}42 \\
33\end{array}$ & $\begin{array}{c}13 \\
9\end{array}$ & $\begin{array}{l}55 \\
52\end{array}$ & $\begin{array}{l}80 \\
85\end{array}$ \\
\hline 9 & VME & $6 \mathrm{~mm}$ & $3 \mathrm{~mm}$ & $\begin{array}{l}35 \\
28\end{array}$ & $\begin{array}{l}13 \\
11\end{array}$ & $\begin{array}{c}11 \\
7\end{array}$ & $\begin{array}{l}69 \\
72\end{array}$ \\
\hline 10 & VME & $6 \mathrm{~mm}$ & $7 \mathrm{~mm}$ & $\begin{array}{l}33 \\
30\end{array}$ & $\begin{array}{l}15 \\
15\end{array}$ & $\begin{array}{l}26 \\
22\end{array}$ & $\begin{array}{l}68 \\
70\end{array}$ \\
\hline
\end{tabular}




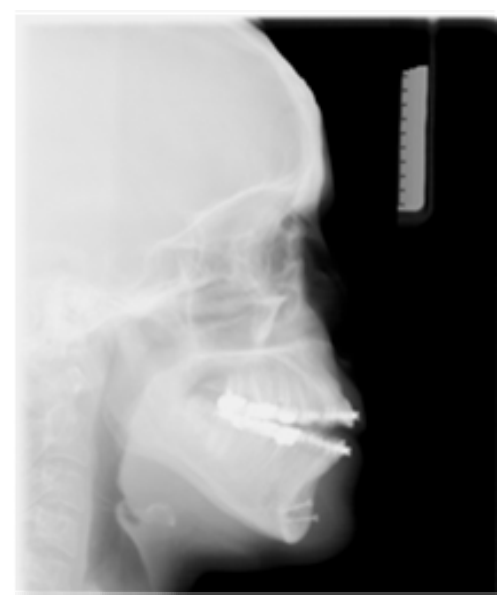

(a)

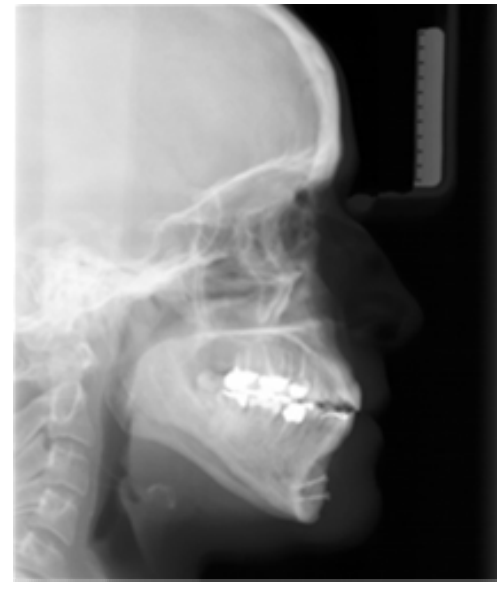

(b)

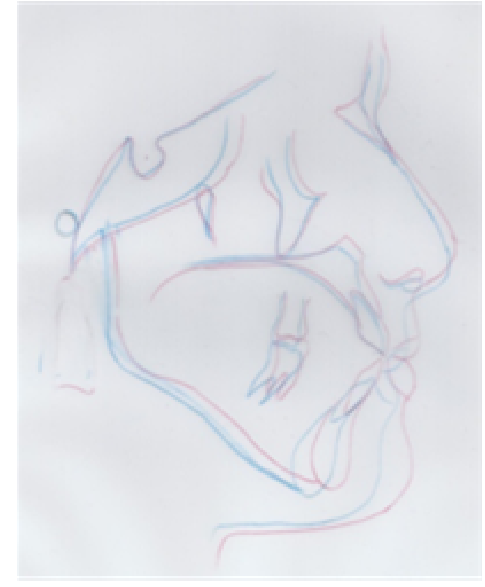

(c)

Figure 1. (a) Lateral cephalometric radiograph before molar intrusion; (b) Lateral cephalometric radiograph after molar intrusion; (c) Lateral cephalometric tracing before molar intrusion (blue) after molar intrusion (red).

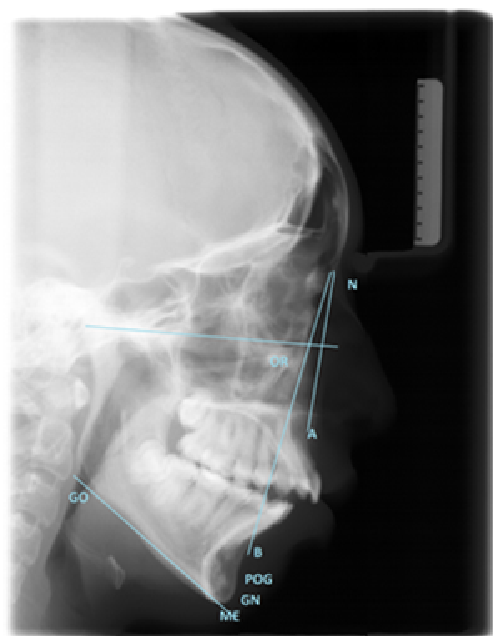

(a)

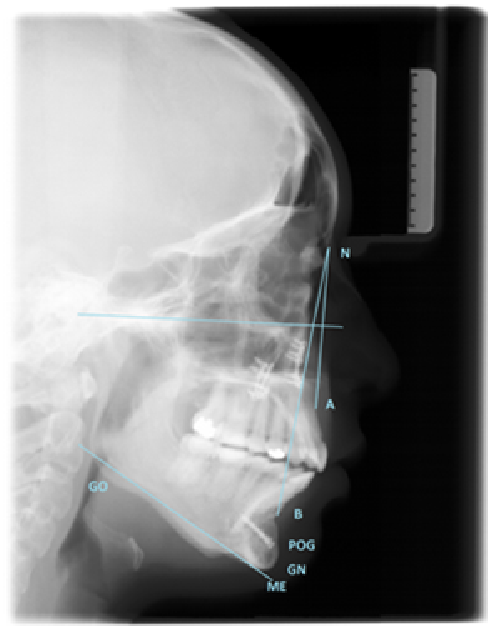

(b)

Figure 2. (a) Lateral cephalometric radiograph before maxillary impaction; (b) Lateral cephalometric radiograph after maxillary impaction.

retrognathic chin and convex profiles were corrected, resulting in a straight profile. The facial proportions were also improved due to of the decrease in the lower facial height. The strain in the circumoral musculature during lip closure was improved.

\section{DISCUSSION}

Many studies in the literature mention the esthetic effects of maxillary Le Fort I impaction related to the resulting mandibular counter clockwise rotation $[1,3,4]$. However, not much is mentioned regarding the effect of molar intrusion on the mandibular plane angle and the resulting esthetic effect. The results of our study showed that molar intrusion used to close anterior open bite gives some esthetic results as seen in maxillary Le Fort I impaction. However, this was not noted in all orthodontically treated cases with anterior open bite.

The esthetic changes resulting from maxillary impaction are mostly related to the degree of mandibular autorotation. The published data on this subject focused mainly on prediction analysis of mandibular autorotation following maxillary impaction $[3,4]$. Chin position was advanced in all patients who underwent Le Fort I impaction and this was noted in the literature by counter clockwise rotation of the mandible and an increase in SNB and NB-Pog. However, we only used SNB to demonstrate the effect of maxillary impaction on mandible position and NB-Pog was not used to demonstrate the amount of postoperative mandibular advancement in patients who underwent maxillary impaction due to the fact that three patients required genioplasty to further improve esthetics. 
Patients who underwent orthodontic treatment for open bite closure showed improved esthetics, however, not all patients showed mandibular counter clockwise rotation as seen in Le Fort I impaction. Some patients showed clockwise mandibular rotation. This was explained by the orthodontic treatment, since two of the patients have constricted maxilla. Expansion appliance such as Quad-Helix was used to expand the maxillary teeth. It is well documented with expansion clock wise rotation of the mandibular plane which has taken place due to extrusion of the palatal cusp. The clock wise rotation point pog will also rotate backward. The difference between pre and post treatment was in average 2 degrees which could be due to the occlusal plane measured at functional occlusion with no anterior teeth contacting a measurement error that was possible. The most important is the reduction of the mandibular plane which showed a counter clock wise rotation in all the patients with esthetic improvement.

On the other hand, the skeletal improvement is poor due to failure to establish absolute anchorage during molar intrusion. To obtain absolute anchorage, several devises have been used such as dental implant [11-14], screws $[15,16]$ and miniplates $[17,18]$. The advantages of these devices are by providing absolute anchorage different teeth movement without the need for patient's cooperation. Several reports have been reported on the use of screw for anchorage in teeth movement, intrusion or retraction of anterior teeth [10,11], and protraction of posterior teeth in the mandible. In addition, few papers have reported the use of titanium screws for orthodontic anchorage to intrude upper and/or lower molars of an adult patient with severe skeletal anterior open bite.

The mandible will follow any changes in occlusion resulting from maxillary impaction or molar intrusion. The noted changes in mandibular and chin position were quite variable and less predictable following molar intrusion, however, the improved esthetics can be appreciated in all patients. Future standardized studies will help us make accurate predictions following molar intrusion or maxillary impaction.

\section{REFERENCES}

[1] Schendel, S., Eisenfeld, J., Bell, W., et al. (1976) Superior repositioning of the maxilla: stability and soft tissue osseous relations. American Journal of Orthodontics, 70, 663-674.

http://dx.doi.org/10.1016/0002-9416(76)90226-8

[2] Sherwood, K. (2007) Correction of skeletal open bite with implant anchored molar/bicuspid intrusion. Oral \& Maxillofacial Surgery Clinics of North America, 19, 339350. http://dx.doi.org/10.1016/0002-9416(76)90226-8

[3] Nadjmi, N., Mommaerts, M., Abeloos, J. and Clercq, C. (1998) Prediction of mandibular autorotation. Journal of
Oral and Maxillofacial Surgery, 56, 1241-1247. http://dx.doi.org/10.1016/S0278-2391(98)90599-7

[4] Y.-C. Wang, Ko, E.W.-C., Huang, C.-S. and Chen, Y.-R. (2006) The inter-relationship between mandibular autorotation and maxillary LeFort I impaction osteotomies. Journal of Craniofacial Surgery, 17, 898-904. http://dx.doi.org/10.1097/01.scs.0000234985.99863.97

[5] Sperry, T.P., Steinberg, M.J. and Gans, B.J. (1982) Mandibular movement during autorotation as a result of maxillary impaction surgery. American Journal of Orthodontics, 81, 116-123.

http://dx.doi.org/10.1016/0002-9416(82)90035-5

[6] Bryan, D.C. (1994) An investigation into the accuracy and validity of three points used in the assessment of autorotation in orthognathic surgery. British Journal of Oral and Maxillofacial Surgery, 32, 363-272. http://dx.doi.org/10.1016/0266-4356(94)90026-4

[7] Nattestad, A. and Vedtofte, P. (1992) Mandibular autorotation in orthognathic surgery: A new method of locating the centre of mandibular rotation and determining its consequence in orthognathic surgery. Journal of Craniofacial Surgery, 20, 163-170.

[8] Rekow, E.D., Speidel, T.M. and Koening, R.A. (1993) Location of the mandibular center of autorotation in maxillary impaction surgery. American Journal of Orthodontics and Dentofacial Orthopedics, 103, 530-536. http://dx.doi.org/10.1016/0889-5406(93)70093-4

[9] Wang, Y., Ko, E., Huang, C. and Chen, Y. (2006) The inter-relationship between mandibular autorotation and maxillary LeFort I impaction osteotomies. Journal of Craniofacial Surgery, 17, 898-904. http://dx.doi.org/10.1097/01.scs.0000234985.99863.97

[10] Alsulaimani, F. (2012) Severe anterior open-bite case treated using miniscrew anchorage: A case report. Journal of American Science, 8, 102-107.

[11] Turley, P.K., Kean, C., Schur, J., Stefanac, J., Gray, J., Hennes, J. and Poon, L.C. (1988) Orthodontic force application to titanium endosseous implants. Angle Orthodontist, 58, 151-162.

[12] Odman, J., Lekholm, U., Jemt, T., Branemark, P.I. and Thilander, B. (1988) Osseointegrated titanium implantsA new approach in orthodontic treatment. European Journal of Orthodontics, 10, 98-105. http://dx.doi.org/10.1093/ejo/10.2.98

[13] Prosterman, B., Prosterman, L., Fisher, R. and Gornitsky, M. (1995) The use of implants for orthodontic correction of an open bite. American Journal of Orthodontics and Dentofacial Orthopedics, 107, 245-250. http://dx.doi.org/10.1016/S0889-5406(95)70139-7

[14] Roberts, W.E., Helm, F.R., Marshall, K.J. and Gongloff, R.K. (1989) Rigid endosseous implants for orthodontic and orthopedic anchorage. Angle Orthodontist, 59, 247 256.

[15] Creekmore, T.D. and Eklund, M.K. (1983) The possibility of skeletal anchorage. Journal of Clinical Orthodontics, 17, 266-269.

[16] Costa, A., Raffainl, M. and Melsen, B. (1998) Miniscrews as orthodontic anchorage: A preliminary report. 
International Journal of Adult Orthodontics \& Orthognathic Surgery, 13, 201-209.

[17] Deguchi, T., Takano-Yamamoto, T., Kanomi, R., Hartsfield Jr., J.K., Roberts, W.E. and Garetto, L.P. (2003) The use of small titanium screws for orthodontic anchorage. Journal of Dental Research, 82, 377-381.

http://dx.doi.org/10.1177/154405910308200510
[18] Adell, R., Lekholm, U., Rockler, B. and Branemark, P.I. (1981) A 15-year study of osseointegrated implants in the treatment of the edentulous jaw. International Journal of Oral Surgery, 10, 387-416.

http://dx.doi.org/10.1016/S0300-9785(81)80077-4 